\title{
Revisiting the study of the life cycles of predatory ground beetles (Coleoptera, Carabidae) in the agrolandscape of the foothill zone of Krasnodar Krai
}

\author{
Eugeniy Khomitskiy ${ }^{1}$, Alexandr Zamotajlov ${ }^{1, *}$, Alexandr Beliy ${ }^{1}$, Leonid Esipenko ${ }^{1,2}$, and \\ Irina Balakhnina ${ }^{2}$ \\ ${ }^{1}$ I.T. Trubilin Kuban State Agrarian University, 13 Kalinina st., 350044, Krasnodar, Russia \\ ${ }^{2}$ All-Russian Research Institute of Biological Plant Protection, p/o 39, 350039, Krasnodar, Russia
}

\begin{abstract}
The article discusses the results of 4-year studies of the demographic structure and life cycles of predatory ground beetles populations in the agrolandscape and adjacent biocenoses of the foothill zone of Krasnodar Krai. The main "residential" and "transit" biotopes of 102 species were identified. It was found that among the studied species 36 ones have a full age structure; currently, life cycles for 4 widespread species in this zone have been completely reconstructed.
\end{abstract}

\section{Introduction}

Despite the significant success achieved in recent years in studying the life cycles of ground beetles in Russia, it should be noted that the latter were reconstructed mainly in natural biocenoses, the life cycles of ground beetles in agrocenoses, including Krasnodar Krai, are still very poorly studied $[1,2,3,4]$. At the same time, with the growing pace of organic farming development in general and in this region in particular $[5,6]$, the search for ways to activate effective non-specific local entomophages is of great importance [7, etc.]. Knowledge of life cycles makes it possible to understand when the maximum activity of ground beetles should be expected, and whether such peaks will be synchronized with the appearance and periods of harmfulness of specific phytophages. Moreover, with the increasing climate changes $[8,9,10,11]$, life cycles also undergo significant transformations, and therefore many years of research are required to determine a common life cycle pattern and its transformation trends for each species. The surrounding forest biocenoses enrich the fauna of neighboring agrolandscapes $[12,13]$, which requires an additional study of the demography of ground beetles of such habitats in similar regions.

\footnotetext{
* Corresponding author: a zamotajlov@mail.ru
} 


\section{Material and methods}

The studies were carried out in agrocenoses of the foothill zone of Krasnodar Krai in the vicinity of Imeretinskaya village (Goryachiy Klyuch) from 2015 to 2019. The material was collected by the method of pitfall traps (or "Barber traps") [14] on 10 plots of agrolandscape and adjacent natural biotopes. The trap consisted of a 0.51 plastic glass with an inlet diameter of $90 \mathrm{~mm}$ filled with a fixing liquid $(150 \mathrm{ml}$ per trap) - $4 \%$ formalin solution, and a lid installed at a height of $2 \mathrm{~cm}$ from the inlet. A series of 10 traps were installed in the experimental plots, the distance between them was 4-10 meters. Material sampling was carried out every decade of the month. Some of the ground beetles in the experimental plots were also manually collected. The imago physiological position was determined by Wallin method [15] with the additions of other authors [16]. In describing life cycles and demographic structure, conventional terminology is used [17].

\section{Results and discussion}

During the research period 11,412 imago ground beetles belonging to 45 genera and 102 species were collected. 75 species were identified in the household plot \#1, in the household plot \# 2 we identified 35 species, in the greenhouse - 33 species, in the field for haying - 41 species, in the layland - 18 species, in the upland forest (2017) - 23 species , in the upland forest (2019) - 17 species, in the forest in the valley of Marta river (2017) - 20 species, in a forest in the valley of Marta river (2019) - 33 species, in the pasture - 34 species. The largest number of species was collected in the plot \# 1, which is associated with a maximum mosaic of microstations, which are formed, obviously, due to the introduction of organic fertilizers, irrigation, tine aisles, and also as a result of the favorable location of the site on the southern exposure of the hill.

As a result of studying the physiological state of ground beetle gonads, demographic spectra of local populations were constructed, based on the completeness of which "residential" and "passage" ("transit") biotopes were identified. It was found that 36 species have a full age and demographic structure in 10 experimental plots: Cicindela germanica (Linnaeus, 1758), Leistus fulvus Chaudoir, 1846, Nebria brevicolli (Fabricius, 1792), Notiophilus rufipes Curtis, 1829, Carabus cumanus Fischer von Waldheim, 1823, Carabus exaratus Quensel, 1806, Clivina fossor (Linnaeus, 1758), Stomis pumicatus (Panzer, 1796), Poecilus cupreus (Linnaeus, 1758), Pterostichus cursor (Dejean, 1828), Pterostichus anthracinus (Illiger, 1798), Pterostichus strenuus (Panzer, 1796), Platynus assimile (Paykull, 1790), Anchomenus dorsalis (Pontoppidan, 1763), Amara tricuspidata Dejean, 1831, Amara eurynota (Panzer, 1796), Amara familiaris (Duftschmid, 1812), Amara lucida (Duftschmid, 1812), Amara ovata (Fabricius, 1792), Dinodes decipiens (Dufour, 1820), Parophonus planicollis (Dejean, 1829), Harpalus rufipes (De Geer, 1774), Harpalus calceatus (Duftschmid, 1812), Harpalus chrysopus Reitter, 1887, Harpalus serripes (Quensel, 1806), Harpalus tardus (Panzer, 1796), Harpalus cupreus Dejean, 1829, Harpalus distinguendus (Duftschmid, 1812), Ophonus azureus (Fabricius, 1775), Ophonus diffinis (Dejean, 1829), Ophonus sabulicola (Panzer, 1796), Microlestes minutulus (Goeze, 1777), Cymindis sp., Brachinus crepitans (Linnaeus, 1758), Brachinus elegans Chaudoir, 1842, and Brachinus explodens Duftschmid, 1812.

We determined the following distribution of species with a complete demographic and age structure in the experimental plots: 17 species were identified in the plot \# 1; in the plot \# 2 - 0 species; in the greenhouse - 6 species; on the field for haying - 8 species; on the layland - 4 species; in the upland forest (2017) - 3 species; in the upland forest (2019) - 3 species; in the forest in the valley of Marta river (2017) - 1 species; in the forest in the 
valley of Marta river (2019) - 5 species; in the pasture - 6 species. The maximum number of species with the full life cycle was also in the plot \# 1 .

Among the above mentioned 36 species, 4 species of ground beetles, $N$. brevicolli, $C$. exaratus, $A$. dorsalis, $H$. tardus, exist in almost all the studied biotopes. Below we describe the results of the reconstruction of the life cycles of these species, the rest will be described in different publications.

Nebria brevicolli (Fig. 1). This species does not undergo hibernation, during the winter, larvae and pregenerative adults are found in the studied habitats, which is explained by the prevailing mild winters, although in other regions there are examples of the activity of these beetles in snowy and frosty winters $[18,19]$. In spring, in March-April, third-age larvae pupate and their juvenile individuals are observed from the second decade of April to the second decade of May. From the first ten days of May to the third ten days of June, immature adults come out, which then fall into summer estivation (from June to September). Then the imago is recorded at the end of September, when the immature, generative and post-generative stages are recorded. The main peak of activity falls on October - November. Egg laying is stretched from October to December. Larvae can be found from January to April and from October to December. Thus, the life cycle of this species can be described as a one-year autumn-winter monocycle.

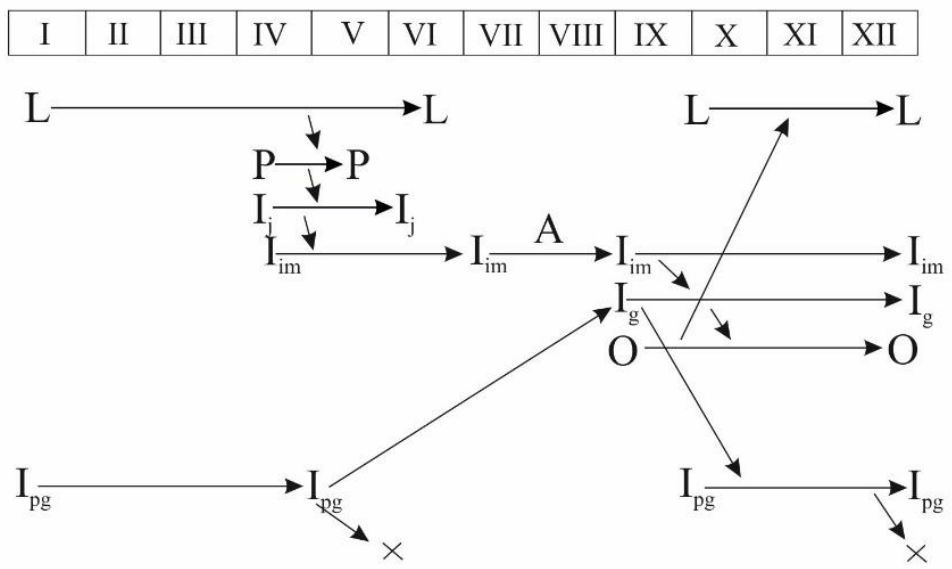

Fig. 1. Life cycle of Nebria brevicolli, legend keys: I-XII - timeline in months; O - an egg; L - larva; P - pupa; I - imago (physiological state: $I_{j}$ - juvenile, $I_{i m}$ - immature (pre-generative), $I_{g}$ - generative, $\mathrm{I}_{\mathrm{pg}}$ - post-generative), $\mathrm{A}$ - estivation

Carabus exaratus (Fig. 2). Reproduction of this species takes place from the end of summer until mid-autumn, but individual generative adults can also be found in spring. Egg laying is stretched and can be observed before leaving for hibernation. Due to the fact that egg laying occurs late and development takes place within two years, larvae, immature and post-generative adults go wintering. According to the published data, larvae of the first instar are found from the second decade of August to mid-November, and larvae of the second instar are found from the first decade of September to mid-November. Larvae of the third instar are observed in autumn (from the first decade of September to the second decade of November) and in spring [2]. Juvenile adults from overwintered larvae emerge from early May to early June. The maximum activity occurs in spring, when juvenile and immature beetles appear, and from late summer to mid-autumn, during the reproductive 
season. A short estivation is observed at the end of July; it is hosted by immature and postgenerative adults. Thus, the life cycle of $C$. exaratus can be described as a two-year summer-autumn recycle.

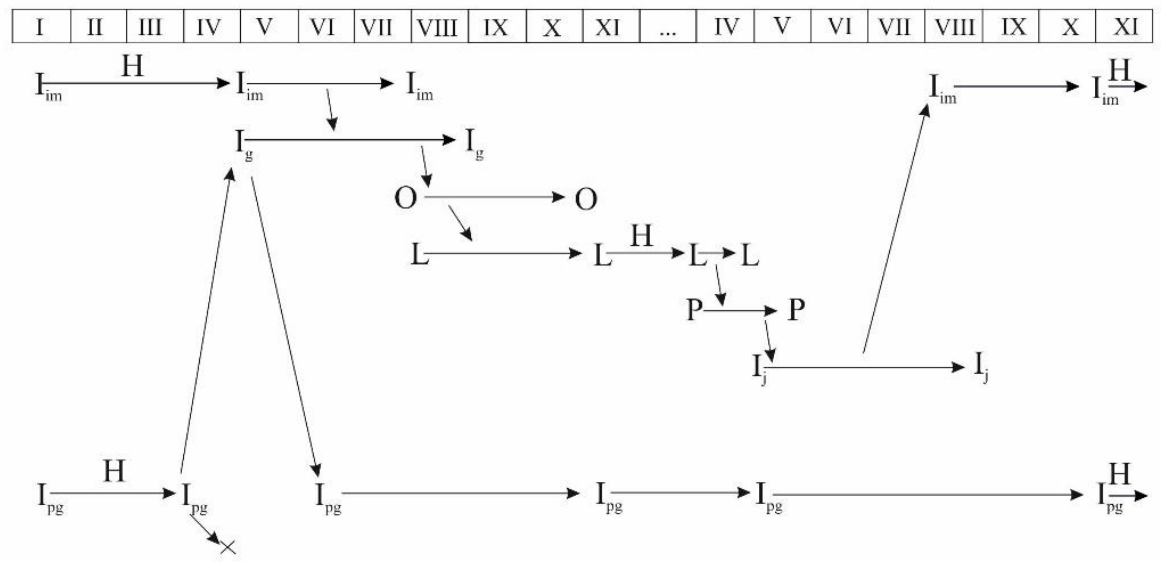

Fig. 2. Life cycle of Carabus exaratus, legend keys: I-XII - timeline in months; O - an egg; L - larva; $\mathrm{P}$ - pupa; I - imago (physiological state: $\mathrm{I}_{\mathrm{j}}$ - juvenile, $\mathrm{I}_{\mathrm{im}}$ - immature (pre-generative), $\mathrm{I}_{\mathrm{g}}$ - generative, $\mathrm{I}_{\mathrm{pg}}$ - post-generative), $\mathrm{H}$ - hibernation

Anchomenus dorsalis (Fig. 3). Wintered beetles are represented by immature adults, the reproductive period is observed from early May to mid-July. The egg laying period is very short, and the larval stage apparently passes very quickly, since a month passes between egg laying and the appearance of juvenile adults. The maximum peak of activity occurs in the second decade of May - the first decade of July due to immature and generative adults. Postgenerative individuals are observed in May. Thus, the life cycle of this species in the foothills of Krasnodar Krai can be characterized as a one-year springsummer monocycle with short developmental periods and wintering at the stage of immature imago.

Harpalus tardus (Fig 4). Immature and postgenerative adults go wintering, then the immature beetles in April become generative, and begin to reproduce, a small part of the generative beetles re-participates in reproduction. The reproductive period of this species in the foothill zone takes five months, starting from the first decade of March and ending with the third decade of July, although there are individual generative adults in February, August, September and November. Postgenerative adults are found from March to August. Juvenile adults have one peak of activity, from July to August. Larvae develop from April to October. Thus, the life cycle of $H$. tardus can be characterized as a one-year springsummer recycle. 


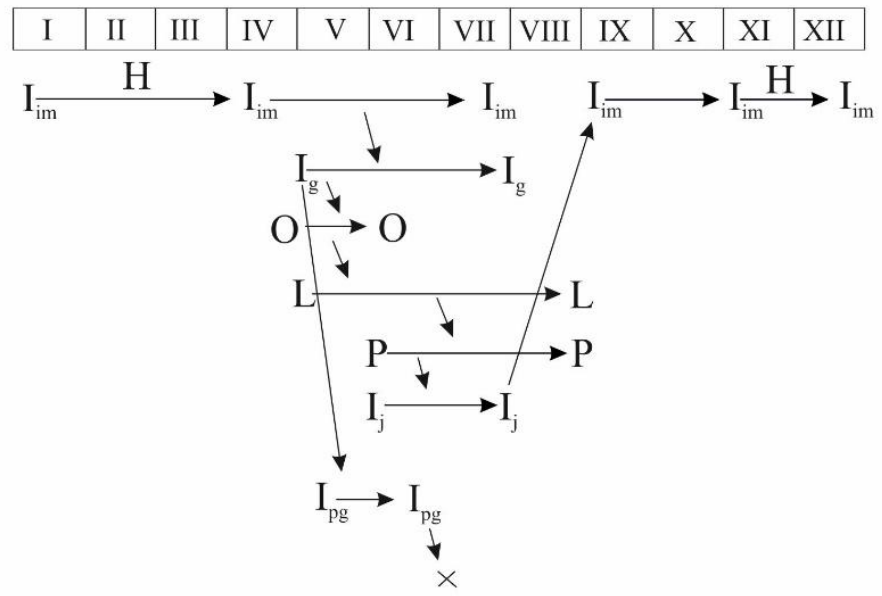

Fig. 3. Life cycle of Anchomenus dorsalis, legend keys: I-XII - timeline in months; O - an egg; L larva; P - pupa; I - imago (physiological state: $I_{j}$ - juvenile, $I_{\text {im }}$ - immature (pre-generative), $I_{g}$ generative, $\mathrm{I}_{\mathrm{pg}}$ - post-generative), $\mathrm{H}$ - hibernation

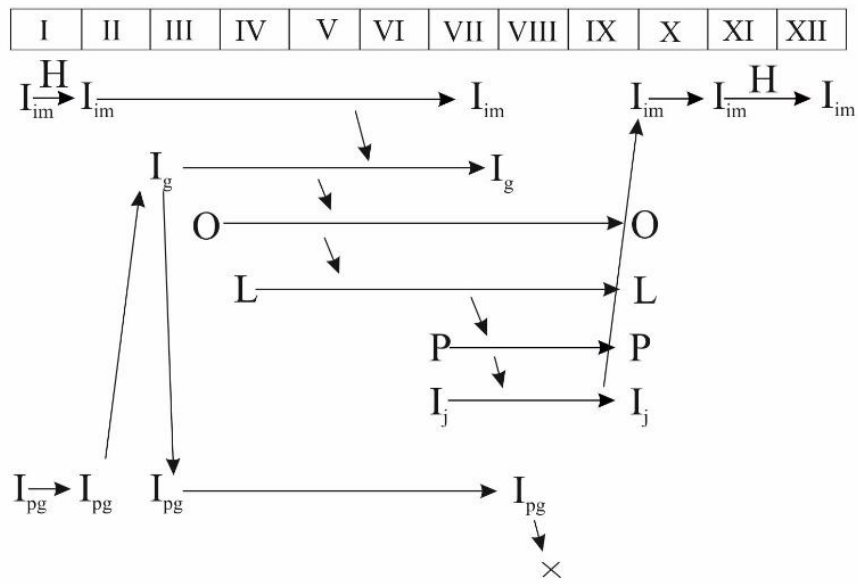

Fig. 4. Life cycle of Harpalus tardus, legend keys: I-XII - timeline in months; O - an egg; L - larva; P - pupa; I - imago (physiological state: $I_{j}$ - juvenile, $I_{i m}$ - immature (pre-generative), $I_{g}$ - generative, $I_{p g}$ - post-generative), $\mathrm{H}$ - hibernation

In conclusion, it should be noted that the most important issues of the implementation of many species life cycles in various biotopes of the agrolandscape still remain disputable. And this, in turn, requires further research and the development of sound practical recommendations on the use of ground beetles in plant protection.

The research was partially supported by the RFBR: (projects 19-44-230004 r_a and 1944-233007 r_mol_a) and state task \#075-00376-19-00 of the Ministry of science and higher education of the Russian Federation in the framework of research on the topic \# 0686-20190010 . 


\section{References}

1. A.S. Bondarenko, Abstract PhD Thesis. Krasnodar (2013)

2. E.E. Bokhovko, Abstract PhD Thesis. Noscow (2006)

3. V.G. Knysh, Abstract PhD Thesis. Krasnodar (2002)

4. A.V. Matalin, Abstract Doc. Biol. Sc. Thesis. Moscow (2011)

5. P.J. Reganold, J.M. Wachter, Nature Plants, 2(2), 15221 (2016) https://doi.org/10.1038/nplants.2015.221

6. E. Rossi, D. Antichi, A. Loni, R. Canovai, M. Sbrana, M. Mazzoncini, Environmental Entomology, 48(6), 1377-1387 (2019) https://doi.org/10.1093/ee/nvz119

7. S.I. Rondon, A. Pantoja, A. Hagerty, D.A. Horneck, Production Florida Entomologist, 96(4), 1492-1499 (2013) https://doi.org/10.1653/024.096.0430

8. I. Chen, J.K. Hill, R. Ohlemuller, D.B. Roy, C.D. Thomas, Science, 333(6045), 1024-1026 (2011) https://doi.org/10.1126/science.1206432

9. A.S. Zamotajlov, V.I. Shchurov, Proc. Kuban Stat. Agr. Univ., 22, 32-39 (2010)

10. M.C. Russell, J. Lambrinos, E. Records, G. Ellen, Biological Control, 106, 54-63 (2017) http://dx.doi.org/10.1016/j.biocontrol.2016.12.008

11. F. Oberholzer, Th. Frank, Biocontrol Science and Technology, 13(1), 99-110 (2013) https://doi.org/10.1080/0958315021000054421

12. I. Carlos, F. Martins, F.J. Cividanes, S. Ide, G.Q. Haddad, Bragantia, 71(4), 471-480 (2013) https://doi.org/10.1590/S0006-87052013005000009

13. G.L. Löovei, T. Magura, Insect Conservation and Diversity, 10(2), 141-150 (2016) https://doi.org/10.1111/icad.12210

14. H. Barber, J. Elisha Mitchell Sci. Soc., 46, 259-266 (1931)

15. H. Wallin, Plant Prot. Rep. Dis. Swedish Univ. Agric. Sci. Uppsala, 15, 3-19 (1987)

16. A.V. Matalin, K.V. Makarov, ZooKeys, 100, 223-254 (2011) https://doi.org/10.3897/zookeys.100.1530

17. A.V. Matalin, Zool. Zhurn., 86, 1196-1220 https://doi.org/10.1134/S0013873807080027

18. R. Jaskuła, A. Soszyńska-Maj, ZooKeys, 100, 517-532 (2011) https://doi.org/10.3897/zookeys.100.1543

19. E.E. Khomitskiy, A.S. Zamotajlov, A.I. Belyi, Proc. Kuban Stat. Agr. Univ., 69, 192-199 (2017) 